\title{
Participação de cooperativas em licitações na perspectiva da política de compras governamentais
}

\author{
Participation of cooperatives in biddings from the perspective of government \\ procurement policy
}

\begin{abstract}
Resumo
Este artigo tem por objetivo caracterizar a participação das sociedades cooperativas em processos licitatórios promovidos pela Administração Pública, e, com esteio nesse conhecimento, se propõe a analisar os resultados obtidos na perspectiva da utilização da política de compras governamentais como plataforma de cumprimento do mandamento constitucional de apoio e estímulo ao cooperativismo. A pesquisa teve como referência o histórico de vedações, limitações, estímulos e possibilidades da participação de cooperativas nas contratações públicas, considerando preceitos legais que envolvem as licitações como instrumento de promoção do desenvolvimento nacional sustentável. Trata-se de pesquisa qualitativa, com utilização de procedimento de análise de conteúdo nos dados referentes aos pregões realizados no período de 2013 a 2018. Como resultado, verificou-se que as sociedades cooperativas possuem pouca representatividade quantitativa e financeira nas contratações públicas realizadas no período analisado.
\end{abstract}

Palavras-chave: Cooperativa. Licitação. Política de Compras Governamentais.

\begin{abstract}
This article aims to characterize the participation of cooperative societies in procurement promoted by Public Administration, and based on the knowledge obtained, it proposes to analyze the results obtained from the perspective of using the government procurement policy as a platform to comply with the constitutional mandate of support and encouragement of cooperativism. The research referred to the historical inhibitions, limitations, incentives and possibilities of cooperatives' participation in public hiring, considering the legal requirements that involve the biddings as an instrument to promote sustainable national development. This is a qualitative research, which uses content analysis procedure of trading sessions carried out from 2013 to 2018. As a result, it was verified that the cooperative societies have little quantitative and financial representativeness in public contracts fulfilled in the mentioned period.
\end{abstract}

Keywords: Cooperative. Procurement. Government Procurement Policy

Kalina Donato Sales

${ }^{\mathrm{I}}$ Universidade de Brasília - UnB, Brasilia, DF. kalinadonato@yahoo.com.br 


\section{Introdução}

A Aliança Cooperativa Internacional (ACI) define as cooperativas como associações autônomas de pessoas, unidas voluntariamente para satisfazer suas aspirações e necessidades econômicas, sociais e culturais comuns, através de um empreendimento de propriedade coletiva do grupo e gerida democraticamente. ${ }^{\mathbf{i}}$

De acordo com a ACI, o desenvolvimento sustentável está na gênese e é a própria natureza do movimento cooperativo e, como tal, as cooperativas podem dar à sociedade contributos específicos e substancialmente diferentes de outros tipos de organizações. Dessa forma, as cooperativas apresentam relevante papel na inclusão e no desenvolvimento de negócios sustentáveis, consistindo em um modelo diferenciado de organização, que deve ser estimulado pela ação do Estado.

As normas constitucionais brasileiras estimulam a formação e atuação do cooperativismo, instituindo inafastável dever, para os entes públicos, nos mais variados campos de atuação administrativa, de prestigiar a organização das sociedades cooperativas.

Uma das formas do Estado exercer a competência regulatória de interferir nas estruturas de mercado é pela política de compras governamentais, na qual o processo licitatório não configura um fim em si mesmo, mas um instrumento de alcance e garantia do interesse público. Nesse escopo, a Lei no 8.666, de 21 de junho de 1993, Lei Geral de Licitações (LGL), determina que a promoção do desenvolvimento nacional sustentável é um dos objetivos da licitação.

A LGL possui também a previsão expressa em seu art. $3^{-0}$ que assegura às sociedades cooperativas o direito à participação no âmbito das licitações públicas, visando a ampliação da competitividade nos certames. Entretanto, o cenário das compras públicas brasileiras tem sido palco de discrepâncias entre iniciativas de estímulo e vedação da participação das cooperativas nos processos de compras públicas.

A partir desses constructos, este estudo tem por finalidade caracterizar a participação das sociedades cooperativas em processos licitatórios promovidos pela Administração Pública, e, com esteio nesse conhecimento, se propõe a analisar os resultados obtidos na perspectiva da utilização da política de compras governamentais como plataforma de cumprimento do mandamento constitucional de apoio e estímulo ao cooperativismo.

\section{Referencial Teórico}

O cooperativismo traz a concepção de um sistema econômico alternativo ou complementar, na medida em que proporciona a distribuição de riqueza de modo mais igualitário entre os responsáveis pela produção, entre o grupo que se coopera.

Na conceituação concebida por Franke (1973), a palavra cooperativismo pode ser tomada em duas acepções, por um lado na que designa o sistema de organização econômica que visa a eliminar os desajustamentos sociais oriundos dos excessos da intermediação capitalista e, por outro, na doutrina corporificada no conjunto de princípios que devem reger o comportamento do homem integrado naquele sistema. Nesse sentido, o fundo ético do sistema cooperativo traduz-se no lema "um por todos, todos por um", que é uma aplicação particular do princípio de solidariedade, a cujo império fica submetida a atividade dos cooperados. (FRANKE, 1973, p.1)

Nos dizeres da Lei no. 5.764, de 16 de dezembro de 1971, lei de regência que definiu a Política Nacional de Cooperativismo e instituiu o regime jurídico das sociedades cooperativistas, as cooperativas são sociedades de pessoas, com forma e natureza jurídica próprias, constituídas para prestar serviços a seus associados. Possuem características que as diferem de outras sociedades, como, por exemplo, não possuírem finalidade lucrativa, limitação do número de quotas-partes do capital para cada associado, singularidade de voto (independentemente do número de cotas partes que possua), neutralidade política e indiscriminação religiosa, racial e social e prestação de assistência aos associados.

No entendimento de Reisdorfer (2014), desde a primeira cooperativa de que se tem registro na história - um armazém, aberto em 1844 por um pequeno grupo de tecelões, com o objetivo de melhorar a situação econômica precária de seus integrantes, o Rochdale Equitable Pioneers Society - 
Sociedade dos Probos Pioneiros de Rochdale, a atuação das cooperativas é pautada por princípios consagrados e reconhecidos mundialmente.

Os princípios, surgidos nessa época, são adotados ainda hoje por 105 países. São as linhas orientadoras pelas quais as cooperativas levam os seus valores à prática: adesão voluntária e livre; gestão democrática; participação econômica dos membros; autonomia e independência; educação, formação e informação; intercooperação; interesse pela comunidade. ${ }^{i i}$

Nos termos da legislação nacional em vigor, adquire a personalidade jurídica a cooperativa quando, arquivados os documentos constitutivos na Junta Comercial, for feita a respectiva publicação. Estão, contudo, obrigadas, para seu funcionamento, a registrarem-se na entidade de representação do sistema cooperativista nacional, a Organização das Cooperativas Brasileiras (OCB) ou entidade estadual, mediante a realização dos procedimentos previstos na Lei Geral das Sociedades Cooperativas.

No Brasil, as cooperativas representam relevante importância econômica. De acordo com a OCB, há mais de 6,8 mil cooperativas no país, com aproximadamente 14,2 milhões de associados e as cooperativas brasileiras geram cerca de 398 mil empregos formais. ${ }^{\text {iii }}$ Essa representatividade está dividida entre os diversos setores econômicos e ramos de atuação. Com o objetivo de organizar internamente suas ações e seus projetos de representação das cooperativas brasileiras, a OCB inicialmente estruturou os ramos do cooperativismo a partir da análise técnica das atividades econômicas exercidas, classificando-os em agropecuário; consumo; crédito; educacional; especial; infraestrutura; habitacional; produção; mineral; trabalho; saúde; turismo e lazer e transporte. Posteriormente a OCB promoveu a reorganização dos ramos por intermédio da Resolução OCB no 56/2019, que regulamenta a classificação dos ramos do cooperativismo, considerando, para cada área de atuação, a legislação societária e específica, a regulação própria, o enquadramento sindical e a quantidade de cooperativas por ramo. Após a reestruturação, o cooperativismo brasileiro passou a ser organizado em sete ramos: agropecuário; consumo; crédito; infraestrutura; trabalho, produção de bens e serviços; saúde e transporte. ${ }^{\text {iv }}$

\subsection{Legislação e jurisprudência de referência}

A Constituição da República Federativa do Brasil, promulgada em o5 de outubro de 1988 (CF/1988), tem como um de seus princípios fundamentais o valor social do trabalho e da livre iniciativa (inciso IV, art. $\mathbf{1}^{\mathbf{o}}$ ), bem como são alguns de seus objetivos construir uma sociedade livre, justa e solidária e garantir o desenvolvimento nacional (incisos I e II do artigo $3^{\circ}$ ). Ao longo do texto do legislador constituinte originário, encontram-se diversos dispositivos de normas que ratificam os referidos princípios e objetivos.

Consagrada no rol dos Direitos e Deveres Individuais e Coletivos, está a Garantia Fundamental de criação de associações e, na forma da lei, de cooperativas, independentemente de autorização, sendo vedada a interferência estatal em seu funcionamento (inciso XVIII, art. $5^{\circ}$ ). A previsão da proteção e fomento ao cooperativismo está ainda nos Títulos destinados à Ordem Econômica e Financeira - dentro dos Princípios Gerais da Atividade Econômica e da Política Agrícola e Fundiária e da Reforma Agrária e ainda dentro das disposições sobre o Sistema Financeiro Nacional. Vejamos:

Art. 174. Como agente normativo e regulador da atividade econômica, o Estado exercerá, na forma da lei, as funções de fiscalização, incentivo e planejamento, sendo este determinante para o setor público e indicativo para o setor privado.

[...] § $2^{\circ}$ A lei apoiará e estimulará o cooperativismo e outras formas de associativismo.

$\S 3^{\circ}$ O Estado favorecerá a organização da atividade garimpeira em cooperativas, levando em conta a proteção do meio ambiente e a promoção econômico-social dos garimpeiros.

$\S 4^{\circ}$ As cooperativas a que se refere o parágrafo anterior terão prioridade na autorização ou concessão para pesquisa e lavra dos recursos e jazidas de minerais garimpáveis, nas áreas onde estejam atuando, e naquelas fixadas de acordo com o art. 21, XXV, na forma da lei. 
Art. 187. A política agrícola será planejada e executada na forma da lei, com a participação efetiva do setor de produção, envolvendo produtores e trabalhadores rurais, bem como dos setores de comercialização, de armazenamento e de transportes, levando em conta, especialmente: [...]

VI - o cooperativismo;

Art. 192. O sistema financeiro nacional, estruturado de forma a promover o desenvolvimento equilibrado do País e a servir aos interesses da coletividade, em todas as partes que o compõem, abrangendo as cooperativas de crédito, será regulado por leis complementares que disporão, inclusive, sobre a participação do capital estrangeiro nas instituições que o integram. (CF/1988, grifo nosso)

Do exposto, é possível inferir que a Constituição Federal estabeleceu um padrão normativo para dar concretude ao que o legislador constituinte originário entendeu essencial - garantir a atuação das sociedades cooperativas em todas as atividades e setores econômicos. Além disso, e por esse motivo, as legislações infraconstitucionais estão imbuídas do dever de legislar no mesmo sentido, do fomento e estímulo às organizações cooperativas.

Muito embora seja evidente o reconhecimento do Estado Brasileiro ao Cooperativismo, o tendo elevado à Garantia Fundamental na Carta Magna, a distorção do modelo cooperativista, pela ação de falsas cooperativas, maculou a sua atuação no mercado, no que diz respeito à sua participação nas contratações públicas.

Na acepção de Machado (2017), a problemática teve origem no contexto do elevado índice de desemprego nos idos da década de 1990, que levou inúmeros grupos de desempregados a se unirem em busca de um objetivo comum que lhes possibilitasse trabalho e renda, fato que resultou no crescimento vertiginoso do número das cooperativas de trabalho. Em 1994, foi incluído nas Consolidações das Leis do Trabalho (CLT) o parágrafo único do artigo 442, que também contribuiu no aumento das cooperativas de trabalho, ao prever que qualquer que seja o ramo de atividade da sociedade cooperativa, não existe vínculo empregatício entre ela e seus associados, nem entre estes e os tomadores de serviços daquela. (CLT/1943)

Tal cenário trouxe, como infeliz consequência, a ação de oportunistas que se aproveitaram do modelo societário cooperativo para burlar e precarizar as relações de trabalho com a formação de falsas cooperativas. De acordo com Gaudio (2014) as cooperativas fraudulentas são meras intermediadoras de mão de obra, não havendo qualquer participação dos cooperados nas decisões da sociedade. A estrutura societária cooperativa é utilizada como fachada para exploração do trabalhador, que desempenha as suas funções obedecendo a uma hierarquia e não de forma coordenada, e orientada pela diretriz da autogestão.

A atuação das falsas cooperativas demandou maior atenção do Ministério Público do Trabalho ao assunto, que resultou na Ação Civil Pública, proposta perante a $20^{\mathrm{a}}$ Vara do Trabalho de Brasília (Processo 01082-2002-020-10-0o-0o). Como resultado, foi homologado o Termo de Conciliação Judicial entre aquele e a União Federal.

Pelo ajuste, a União Federal deveria se abster de contratar trabalhadores por meio de cooperativas de mão de obra, quando estivesse presente necessariamente a relação de subordinação, quer em relação ao tomador ou em relação ao fornecedor dos serviços. O termo de conciliação trouxe extenso rol taxativo de atividades sujeitas à vedação de contratação por cooperativas, partindo da premissa de que é possível arrolar em listagem genérica todos os serviços que, supostamente, seriam exercidos com subordinação dos trabalhadores, criando uma presunção absoluta de que tais serviços implicam em fornecimento de mão de obra e, portanto devem ser vedados.

O Tribunal de Contas da União (TCU) corroborou com o entendimento de restrição à contratação de cooperativas nas decisões por ele proferidas, e, tendo como precedentes o Acórdão no 22/2003, o Acórdão no 23/2003, o Acórdão no 1815/2003, o Acórdão no 2172/2005, o Acórdão no 724/2006 e o Acórdão no 975/2005, editou a esse respeito súmula de vedação que prevê a vedação da participação de cooperativas em licitação quando, pela natureza do serviço ou pelo modo como é usualmente executado no mercado em geral, houver necessidade de subordinação jurídica entre o obreiro e o contratado, bem como de pessoalidade e habitualidade. (SÚMULA TCU 281)

Nesse escopo, é importante salientar que orbita extensa gama de interpretações doutrinárias e jurídicas em torno da caracterização de tais relações de subordinação entre as partes. Dentre 
outros, se distinguem conceitos de subordinação técnica e subordinação jurídica, onde, na acepção de Machado (2017) a subordinação técnica é inerente a qualquer prestação laboral coletiva e não se confunde com a subordinação jurídica, que é requisito da relação de emprego. Assim, a prestação de serviços naturalmente subordinados pode ocorrer, ou não ocorrer, de forma juridicamente subordinada. Por sua vez, as ações discriminatórias para a participação de cooperativas de trabalho em processos licitatórios pressupõem a existência de subordinação jurídica nas atividades de terceirização de mão de obra. Tal entendimento é equivocado, conforme concebido por Machado (2017), pois

[...] não existe legislação no arcabouço jurídico brasileiro que tenha classificado atividades que por sua natureza seriam subordinadas. [...] Há evidente descompasso com as disposições constitucionais e infraconstitucionais nesse tratamento que tem sido dispensado às cooperativas de trabalho. A manutenção de entendimento diverso possibilita por dedução lógica, reconhecer a existência de subordinação jurídica por antecipação e "por atacado", antes mesmo da existência da relação de fato. (MACHADO, 2017)

Noutra seara, um novo horizonte norteou a possível solução para esse histórico prejudicial à atividade do cooperativismo. Isso por que, se por um lado a atividade de execução do Estado andava de encontro com o desejo da Constituição Federal de fomento do cooperativismo, por outro, a atividade legislativa do Estado foi ao encontro da mens legis do constituinte originário.

Corroborando com esse entendimento, pode ser citado o trecho da exposição de motivos do Projeto de Lei no 7009/2006, que deu que origem à Lei que dispõe sobre a organização e o funcionamento das Cooperativas de Trabalho, quando consigna que:

A Constituição da República Federativa do Brasil determina, no § 2 o do artigo 174, que a lei apoie e estimule o cooperativismo e outras formas de associativismo, ficando claro que as cooperativas revelam-se como um instrumento de desenvolvimento local e regional que permite o estabelecimento de formas democráticas no espaço da produção e, por isso, devem ser aprendidas como um valioso recurso no processo de construção da cidadania". (PL 7009/2006)

Assim, em 19 de julho de 2012, foi promulgada a Lei no. 12.690, trazendo extenso rol de direitos aos cooperados. A medida ocupou-se de inserir no arcabouço legislativo dispositivos para diminuir o estigma estereotipado da utilização da cooperativa como instrumento de fraude aos direitos trabalhistas do cooperado. Conforme análise de Gaudio (2014):

Os dois grandes eixos utilizados pela nova lei para combater desvio nas cooperativas de trabalho na nova lei foram: a) o incremento dos mecanismos de gestão democrática do empreendimento cooperativo (ou de autogestão ou de governança cooperativa) e b) a incorporação de direitos sociais do trabalhador, ligados essencialmente à saúde e segurança, como custo mínimo do empreendimento coletivo. (GAUDIO, 2014)

Como legados da legislação, de interesse para este estudo, destacam-se duas vertentes: a primeira consiste no intuito do legislador de rechaçar as chamadas falsas cooperativas, conforme dispõe o art. $5^{\circ}$, ao disciplinar que a Cooperativa de Trabalho não pode ser utilizada para intermediação de mão de obra subordinada; a segunda consiste no mandamento disposto no $§ 2^{\circ}$, do art. 10, ao prever que a Cooperativa de Trabalho não poderá ser impedida de participar de procedimentos de licitação pública que tenham por escopo os mesmos serviços, operações e atividades previstas em seu objeto social.

\subsection{Política de Compra Governamental}

A partir desse entendimento e adentrando no escopo das contratações públicas, ressalta-se que a Lei n. 8666, de 21 de junho 1993, Lei Geral de Licitações (LGL), veio regulamentar o art. 37, XXI, $\mathrm{CF} / 88$, instituindo as normas gerais para licitações e contratos da Administração Pública, no âmbito dos Poderes da União, dos Estados, do Distrito Federal e dos Municípios. 
O instituto da licitação compreende o procedimento administrativo disciplinado por lei e por um ato normativo prévio, que determina critérios objetivos de seleção da proposta de contratação mais vantajosa, com observância do princípio da isonomia, conduzido por um órgão dotado de competência específica. (JUSTEN FILHO, 2009, p. 374)

A evolução histórica das compras governamentais no Brasil está estritamente relacionada à atuação da Administração Pública na consecução do interesse público, tendo sofrido substancial readequação ao longo dos anos em razão das constantes transformações políticas, sociais e econômicas e com a inserção do Estado brasileiro como agente condutor da economia e da aquisição de bens e serviços. (GUEDES, 2013; NASCIMENTO, 2014)

Conforme aponta Baradel (2011), é recorrente a visão do tema licitação com o olhar das políticas públicas, rejeitando a tradicional e simplista visão exclusiva de atividade meio e vislumbrando as finalidades que podem ser alcançadas por meio das contratações públicas. Considerando que o dever de licitar pressupõe a disputa seletiva isonômica para possibilitar ao Estado a escolha da melhor proposta, o seu afastamento ou mitigação, por meio de regras de preferência, proteção de grupos econômicos e definição de tecnologia aplicável, assume caráter de política governamental. Nesse contexto, o termo "política de compras governamentais" expressa a ideia de que, subjacente à compra, existe uma política do Estado, que envolve metas/objetivos. É frequente o uso da política de compras governamentais para alcançar objetivos como estímulo à atividade econômica, geração de empregos, inovação tecnológica e proteção de empresas domésticas. (INÁCIO, RIBEIRO, 2014)

Os caminhos para que a licitação seja utilizada como instrumento de política pública são factíveis pelo uso do poder de compra do Estado, que pela sua elevada envergadura possui a capacidade de produzir impacto direto no mercado. As compras governamentais representaram uma média significativa de 13,8\% do Produto Interno Bruto (PIB) no período de 2006 a 2012. (INÁCIO, RIBEIRO, 2014)

Nesse diapasão, consoante Oliveira (2012), diplomas legais atinentes às licitações públicas têm sido editados para dar concretude à intervenção indireta por indução do Estado na ordem econômica, demonstrando que o caráter interventivo visa à tutela de valores sociais, éticos, econômicos e políticos que transcendem a mera regulação de falhas de mercado. Ainda no entendimento de Oliveira (2012) tais instrumentos possuem o escopo de desenvolver atividades consideradas imprescindíveis ao progresso do país, buscar justiça social e econômica apta a assegurar a neutralização das diferenças existentes, proteger o desenvolvimento nacional da interferência internacional e promover o desenvolvimento nacional sustentável.

Não obstante as restrições impostas à participação das sociedades cooperativas nas licitações, notadamente a Súmula TCU no 281, é de interesse deste estudo identificar ações do Estado exercidas por meio de políticas de compras governamentais a fim de dar concretude aos mandamentos constitucionais de apoio e incentivo ao cooperativismo. Como delimitação, destaca-se que não será objeto de análise os programas governamentais que possuem sistemática de compra direta, a exemplo do Programa Nacional de Alimentação Escolar (PNAE), Programa de Aquisição de Alimentos (PAA).

Nesse escopo, inicialmente, destaca-se a Lei no 11.488 , de 15 de junho de 2007 , que cria o Regime Especial para Incentivos para o Desenvolvimento da Infraestrutura (REIDI) e possui no seu artigo 34 redação que prevê:

"Art. 34 - Aplica-se às sociedades cooperativas que tenham auferido, no anocalendário anterior, receita bruta até o limite definido no inciso II do caput do art. 30 da Lei Complementar no ${ }^{123}$, de 14 de dezembro de 2006, nela incluídos os atos cooperados e não-cooperados, o disposto nos Capítulos V a X, na Seção IV do Capítulo XI, e no Capítulo XII da referida Lei Complementar". (BRASIL, 2007)

A Lei Complementar no 123/2006, alterada pela Lei Complementar no 147, de 7 de agosto de 2014, confere às microempresas e empresas de pequeno porte (ME/EPP) tratamento diferenciado e simplificado nas contratações públicas, e, com esteio em seu art. 47, tal benefício tem como objetivo a promoção do desenvolvimento econômico e social no âmbito municipal e regional, a ampliação da eficiência das políticas públicas e o incentivo à inovação tecnológica. Conforme se colige desse 
diploma legal, em apertada síntese, o tratamento diferenciado e simplificado concedido às ME/EPP consiste na dilação de prazo para comprovação de regularidade fiscal e trabalhista, preferência de contratação como critério de desempate, exclusividade na participação em processos licitatórios cujo valor seja de até R\$ 8o mil, possibilidade da exigência de sua subcontratação em licitações de obras e serviços, além do estabelecimento de cota exclusiva de até $25 \%$ em certames para aquisição de bens de natureza divisível.

Ao estender para as cooperativas o tratamento diferenciado concedido às ME/EPP nas contratações públicas, o Estado cristalizou a intenção do uso da envergadura do seu poder de compra como instrumento indutor para garantir e assegurar a essas sociedades legítimo acesso no espaço de atuação destinado aos fornecedores de bens e serviços do Estado.

No entanto, lançando sombras na legitimidade das cooperativas para usufruírem desse benefício, o Decreto no 8.538, de o6 de outubro de 2015 ao regulamentar o tratamento favorecido, diferenciado e simplificado nas contratações públicas de bens, serviços e obras no âmbito da administração pública federal, restringiu o seu alcance apenas às sociedades cooperativas de consumo.

A segunda ação do Estado a ser destacada na seara do apoio e incentivo ao cooperativismo é Lei oㅜ 12.349, de 15 de dezembro de 2010, que alterou a LGL inserindo no inciso I, § $1^{\circ}$, art. $3^{\circ}$, a vedação expressa aos agentes públicos de admitir, prever, incluir ou tolerar instrumentos convocatórios que apresentem cláusulas que comprometam, restrinjam ou frustrem o caráter competitivo do certame, inclusive nos casos de sociedades cooperativas. A alteração do inciso I, $\S 1^{-}$, do art. 3ㅜㅡ, da Lei no 8.666/93 foi decorrente da Emenda Aditiva no 017 à Medida Provisória no 495, de 2010, na qual consta o texto de justificativa da proposição e de onde depreende-se que o legislador inseriu no texto da LGL o trecho "inclusive nos casos de sociedades cooperativas" especificamente para assegurar que os editais elaborados pela Administração Pública não estabelecessem restrição ou frustação ao direito de participação das cooperativas em processos licitatórios. ${ }^{\mathrm{N}}$

\subsection{Licitação como instrumento do desenvolvimento nacional sustentável}

Com outro viés, na análise de Fenili (2018), o cerne normativo da interface entre licitações e

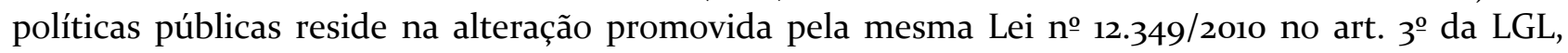
inserindo a promoção do desenvolvimento nacional sustentável como um dos objetivos a serem alcançados pelas licitações públicas. Dessa forma, a proposta mais vantajosa para a Administração Pública deixa de ser aquela que apenas demonstra possuir a melhor relação direta de custo-benefício e passa a ser a que também propicia, mesmo que em longo prazo, benefícios sociais, ambientais e econômicos duradouros para o país. No entendimento de Acocella e Rangel (2013), a função regulatória da licitação manifestou-se nesse normativo em função do objetivo do desenvolvimento sustentável consubstanciado em mecanismos que estabelecem tratamentos mais benéficos a empresas que exercem suas atividades buscando o desenvolvimento do país.

Nesse escopo, para Fenili (2018), o desenvolvimento é tido por sustentável quando age em prol da melhora na qualidade de vida das pessoas inseridas em determinada comunidade, garantindo-lhe fluxo satisfatório de capital nos diversos segmentos da sociedade e resguardando-se os recursos naturais para uso permanente.

Mister destacar, nesse sentido, que as sociedades cooperativas tiveram sua participação nas licitações assegurada pelo mesmo diploma legal que incluiu na LGL o desenvolvimento nacional sustentável como um dos objetivos a serem alcançados pelas contratações públicas. Embora não tenha sido identificada literatura que estabeleça relação direta desses fatos, é possível traçar relevantes pontos de convergência entre a atuação das cooperativas e o desenvolvimento sustentável.

No intuito de promover essa aproximação, esta pesquisa ancora-se precipuamente nas decisões emanadas por ocasião da Cúpula das Nações Unidas para o Desenvolvimento Sustentável, ocorrida em setembro de 2015, e que culminaram na adoção dos Objetivos de Desenvolvimento Sustentável global (ODS). O plano de ação para erradicar a pobreza, proteger o planeta e garantir que as pessoas alcancem a paz e a prosperidade foi consolidado na Agenda 2030, que contempla os 17 ODS desdobrados em 169 metas, das quais o Brasil é signatário. Os 17 objetivos são integrados e 
indivisíveis, e mesclam, de forma equilibrada três dimensões do desenvolvimento sustentável, a dimensão econômica, a social e a ambiental. A consecução dos ODS está vinculada à ação dos governos, da sociedade civil, setor privado e a todos os cidadãos na jornada coletiva para um 2030

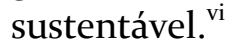

Como alinhamento originário das cooperativas aos ODS, destaca-se que a Aliança Cooperativa Internacional (ACI), representante global do movimento cooperativista, instituiu o alinhamento entre a visão das Nações Unidas e do movimento cooperativista em prol do desenvolvimento sustentável global. Dessa forma, a ACI é umas das organizações não governamentais parceiras da ONU na implantação da Agenda 2030 e assumiu o compromisso de fomentar os ODS em seus países membros.

A OCB, juntamente com o Serviço Nacional de Aprendizagem do Cooperativismo, em alinhamento às diretrizes da $\mathrm{ACI}$, assinou em julho de 2018 um memorando de entendimento com o Programa das Nações Unidas para o Desenvolvimento (PNUD) da ONU. Não obstante as atividades das cooperativas brasileiras já possuírem vinculação com as iniciativas da ONU desde os Objetivos de Desenvolvimento do Milênio (ODM), a partir do instrumento firmado, todas as ações de responsabilidade social desenvolvidas pelas cooperativas estarão ainda mais alinhadas aos ODS propostos pela ONU, visando o atingimento das metas estabelecidas na Agenda 2030. ${ }^{\text {vii }}$

Nesse diapasão, verifica-se, salvo melhor juízo, ser factível estabelecer relação de convergência entre a atuação das cooperativas em prol do desenvolvimento nacional sustentável, sendo ambos constructos da Lei oㅜ 12.349/2010.

\subsection{Cenário Jurídico}

Por derradeiro, adentrando nos cenários jurídicos identificados neste estudo e que apresentam potencial para que o cooperativismo seja melhor utilizado como plataforma de política de compras governamentais em prol do desenvolvimento de negócios sustentáveis, cabe destacar duas possíveis mudanças no arcabouço normativo e jurisprudencial que circundam a contratação de cooperativas nas licitações públicas.

O primeiro é o Projeto de Lei no 1292/1995 e seus apensados, que tramita em regime de urgência no âmbito do Congresso Nacional, o qual contém dispositivo a ser inserido na nova lei de licitações, com intuito de disciplinar a participação de cooperativas nos certames realizados no âmbito da Administração Pública, vejamos:

\footnotetext{
"Art. 14. Os profissionais organizados sob a forma de cooperativa podem participar de licitação quando:

I - a constituição e o funcionamento da cooperativa observarem as regras estabelecidas na legislação aplicável, em especial a Lei oㅜ 5.764, de 16 de dezembro de 1971, a Lei no 12.69o, de 19 de julho de 2012 e a Lei Complementar no 130, de 17 de abril de 2009;

II - a cooperativa apresentar demonstrativo de atuação em regime cooperado, com repartição de receitas e despesas entre os cooperados;

III - qualquer cooperado, com igual qualificação, for capaz de executar o objeto contratado, sendo vedado à Administração indicar nominalmente pessoas;

IV - em se tratando de cooperativas enquadradas na Lei no 12.690 , de 19 de julho de 2012, o objeto da licitação se referir a serviços especializados constantes do objeto social da cooperativa, a serem executados de forma complementar à sua atuação". viii (PL 1292/1995 e apensados)
}

Assim, verifica-se que, apesar de não haver texto definitivo para o novo estatuto das licitações e considerando que o projeto de lei para modernização do arcabouço normativo ainda tramita na Câmara dos Deputados, podendo sofrer alterações no decorrer do processo de aprovação, fica clara a intenção do legislador de promover a pacificação no tocante à participação de cooperativas nas licitações públicas. Na hipótese de que esse artigo se concretize, configura-se em um grande marco para a inserção das cooperativas brasileiras no rol de fornecedores da Administração Pública e da ação do Estado para o fomento ao cooperativismo. 
O segundo ponto de destaque está na jurisprudência do TCU e refere-se ao recente Acórdão TCU no 2463/2019, da Primeira Câmara, cujo enunciado aponta o entendimento daquela Corte de Contas de que a vedação à participação de cooperativas em licitação não deve levar em conta a natureza do serviço a ser contratado, sob pena de violação do art. 10 da Lei 12.690/2012, o qual admite a prestação, pelas cooperativas, de qualquer gênero de serviço, operação ou atividade, desde que prevista em seu objeto social. E ainda:

(...) o termo de conciliação judicial entre a União e o MPT havia sido homologado, em 2003, em decorrência da constatação de que algumas cooperativas só haviam sido criadas para burlar a legislação trabalhista. De acordo com o relator, com a edição das Leis 12.349/2010 e 12.690/2012, teria sido inaugurado um novo regramento jurídico acerca das cooperativas, motivo a demandar uma revisão da Súmula TCU 281 (...) Por conseguinte, "a preocupação que deve exercer o ente público federal não é com a natureza do serviço a ser contratado, mas com a inidoneidade da cooperativa. $\mathrm{O}$ órgão ou entidade pública deverá certificar-se quanto à regularidade de tais sociedades e à relação mantida com seus cooperados, além de exigir a prestação do serviço de forma coordenada, nos termos do art. $7^{\circ}$, § $6^{\circ}$, da referida norma”. (Acórdão TCU no 2463/2019, Primeira Câmara). ${ }^{\text {ix }}$

Nessa decisão, vislumbra-se uma centelha de lucidez na direção da compreensão de que, conforme Machado (2017), as fraudes praticadas por uma minoria de falsas cooperativas não podem desacreditar uma forma de organização centenária, reconhecida e recomendada pelas normas internacionais e consagrada pela Carta Magna brasileira.

\section{Metodologia}

Esta seção tem por finalidade apresentar os métodos e as técnicas utilizada s nesta pesquisa, a fim de evidenciar os procedimentos adotados para coleta de dados e análise das informações. Considerando o objetivo de caracterizar a participação das cooperativas nos processos de licitação pública na perspectiva da política de compras governamentais, a pesquisa realizada foi identificada como qualitativa e de natureza exploratória.

A abordagem qualitativa está pautada na descoberta do novo e no desenvolvimento de teorias empiricamente fundamentadas ao invés de testar aquilo que já é conhecido. Considerando as colocações de Lakatos e Marconi (2008), as pesquisas qualitativas têm a necessidade de analisar e interpretar profundamente o fenômeno para que se tenha condições de descrever a complexidade do objeto analisado. Já a natureza exploratória desta pesquisa justifica-se em decorrência da inexistência de grande volume de estudos anteriores que tenha tratado da caracterização da participação das cooperativas em processos de contratação pública. Quanto ao procedimento de pesquisa, foi utilizada a análise documental, que se caracteriza pela utilização de documentos de todos os tipos, escritos ou não, para a coleta de dados (LAKATOS e MARCONI, 2008).

No processo de coleta de dados para analisar os processos licitatórios com ênfase no objetivo desta pesquisa, foi utilizado inicialmente o Painel de Compras, ferramenta disponibilizada pelo Governo Federal brasileiro, tendo por fundamento a Lei oㅡ 12.527, de 18 de novembro de 2011, denominada Lei de Acesso à Informação (LAI). O Painel de Compras reúne os principais números das contratações públicas e tem por finalidade oferecer um panorama dos gastos públicos e do comportamento licitatório no âmbito da Administração Pública Federal, permitindo a criação de indicadores e consultas personalizadas. ${ }^{\mathrm{x}}$

As contratações públicas sistematizadas e disponibilizadas na referida ferramenta são as realizadas a partir do ano de 2013 , em atendimento à LAI, motivo pelo qual foi delimitado o período de 2013 a 2018 a ser contemplado nesta pesquisa. Inicialmente, de acordo com os dados disponibilizados no Painel de Preços, verificou-se que em 95,54\% dos processos licitatórios realizados no período em análise foi utilizada a modalidade pregão, fato que justifica sua delimitação para fins deste estudo. Posteriormente, realizou-se a busca dos processos de compras por meio de acesso à página do Painel de Compras do Governo Federal, na funcionalidade 
denominada Fornecedores. Com a finalidade de buscar as informações pretendidas, foi selecionada a funcionalidade "faça você mesmo", que dispõe de vinte e quatro filtros de dimensão da busca, e quatro filtros de métrica da busca. Entre as dimensões de busca foi incluído o filtro denominado "porte do fornecedor". Após análise dos dados gerados pela ferramenta, constatou-se que a sistematização das informações não permitia a identificação dos fornecedores cadastrados como sociedades cooperativas.

Dessa forma, diante da impossibilidade de obtenção das informações por meio do acesso ao Painel de Compras, recorreu-se ao Sistema Eletrônico do Serviço de Informações ao Cidadão (eSIC), o qual permite que qualquer pessoa, física ou jurídica, encaminhe pedidos de acesso à informação, acompanhe o prazo e receba a resposta da solicitação realizada para órgãos e entidades do Executivo Federal, tendo por amparo a LAI.

Em resposta tempestiva ao pedido protocolizado no e-SIC, os dados solicitados foram recebidos compilados em planilha do programa Microsoft Excel, contendo as informações relacionadas a 2502 pregões ocorridos no período de 2013 a 2018 que tiveram como vencedores sociedades cooperativas.

A análise dos dados foi conduzida inicialmente para classificar os processos de compra de acordo com o objeto da contratação. Para tanto, a partir da análise individualizada da descrição contida no objeto das licitações e do nome das cooperativas vencedoras, procedeu-se a criação de categorias de acordo com a área da atividade econômica envolvida na contratação. De acordo com Minayo (2001, p.70), a palavra categoria está relacionada a um conceito que abrange elementos com características comuns ou que se relacionam entre si, as categorias são empregadas para se estabelecer classificações.

Diante do exposto, foram identificadas cinco categorias de objeto nos pregões analisados, relacionadas a grandes áreas de atividades econômica: agropecuário, transporte, saúde, consumo e produção de bens e serviços. Nessa seara, é imperioso destacar a impossibilidade de classificar os processos de acordo com os ramos do cooperativismo, pelo fato de haver objetos híbridos, para os quais a delimitação em um dos ramos seria definida de forma subjetiva, sem a precisão exigida na pesquisa científica. Nesse diapasão, a categoria de atividade definida como produção de bens e serviços agrupa os processos licitatórios cujo objeto não está abrangido nas demais categorias e envolve a participação de cooperativas que atuam na produção de bens (industrial, agroindustrial, têxtil, panificação) e na prestação de serviços específicos não contemplados nas demais categorias (cooperativas de trabalho em áreas específicas, cooperativas de serviços ambientais, cooperativas de profissionais específicos, cooperativas de serviço de pesquisa).

Em sequência, com a finalidade de caracterizar a participação quantitativa e financeira das cooperativas nos pregões realizados no âmbito da Administração Pública no período de 2013 a 2018, foram definidos os indicadores a serem mensurados: (i) evolução temporal do quantitativo e do valor dos processos licitatórios em que configuram as sociedades cooperativas como vencedoras do certame; (ii) evolução temporal da participação da área de atividade das cooperativas vencedoras dos processos de compras públicas; (iii) evolução temporal do valor das contratações de acordo com a área de atividade das sociedades cooperativas vencedoras dos processos de compras públicas; (iv) participação da área de atividade no quantitativo de processos de compras vencidos por sociedades cooperativas; (v) participação da área de atividade no valor dos processos de compras vencidos por sociedades cooperativas; e (vi) relação existente entre a quantidade de processos de compras por a área de atividade e o valor movimentado nas contratações.

A análise dos dados possibilitará, ainda, traçar o panorama comparativo entre o resultado obtido na participação das sociedades cooperativas em relação ao total de pregões realizados no âmbito da Administração Pública. A comparação desses resultados permitirá firmar o entendimento acerca da efetividade das ações de fomento da política de compras governamentais, a fim de que o poder de compra do Estado seja utilizado como plataforma de apoio e estímulo ao cooperativismo, com fulcro nos mandamentos da Constituição Federal. 


\section{Resultados e discussões}

Os dados que possibilitaram chegar aos resultados desta pesquisa foram disponibilizados pelo Governo Federal em atenção à LAI, no formato de arquivo do aplicativo Excel, contendo inicialmente informações acerca de $\mathbf{2 5 0 2}$ processos de compras vencidos por sociedades cooperativas no período compreendido entre 2013 e 2018. Na análise das informações, foi identificada a necessidade de realizar ajustes no banco de dados, a fim de obter fidedignidade nos resultados a serem aferidos. Dessa forma, foram excluídos do banco de dados inicial 503 processos relacionados a empresa mercantil que constava equivocadamente identificada como cooperativa.

Assim, o quantitativo total de licitações realizadas no período em análise e que tiveram como vencedoras as sociedades cooperativas é da ordem de 1999 processos de compras. Tais processos envolveram o montante financeiro de $\mathrm{R} \$ 1.665 .284 .629,70$ (um bilhão, seiscentos e sessenta e cinco milhões, duzentos e oitenta e quatro mil, seiscentos e vinte e nove reais e setenta centavos) no valor homologado dos certames. Foi possível constatar que o total de 134 cooperativas foram vencedoras dos pregões analisados.

Da análise dos 1999 processos de compra, conforme procedimentos descritos na metodologia, foi possível obter os resultados almejados nos indicadores definidos para caracterizar a participação quantitativa e financeira das cooperativas nos processos de licitação pública realizados na modalidade pregão. Ressalta-se que os resultados financeiros e percentuais serão apresentados em valores aproximados.

Para o indicador (i), cujo objetivo foi verificar a evolução temporal do quantitativo e do valor dos processos licitatórios em que configuram as sociedades cooperativas como vencedoras os resultados obtidos apontam a diminuição ocorrida no decorrer do espaço temporal definido a partir de 2013, conforme se visualiza no gráfico 1. O maior decréscimo ocorreu no resultado de 2013 para 2014, com queda de $48 \%$ no número de processos licitatórios homologados às cooperativas, em decorrência de 557 processos vencidos em 2013 e 269 em 2014. De 2014 a 2018, o resultado apresenta maior homogeneidade, com a média de 292 processos de compras vencidos por sociedades cooperativas. Em relação ao valor homologado nas licitações vencidas pelas cooperativas, verificouse que o ano de 2014 apresentou o maior montante envolvido nos certames homologados, com o valor de R 597 milhões. O menor montante financeiro foi registrado no ano de 2016, no qual o valor homologado às cooperativas foi da ordem de $\mathrm{R} \$ 51$ milhões.

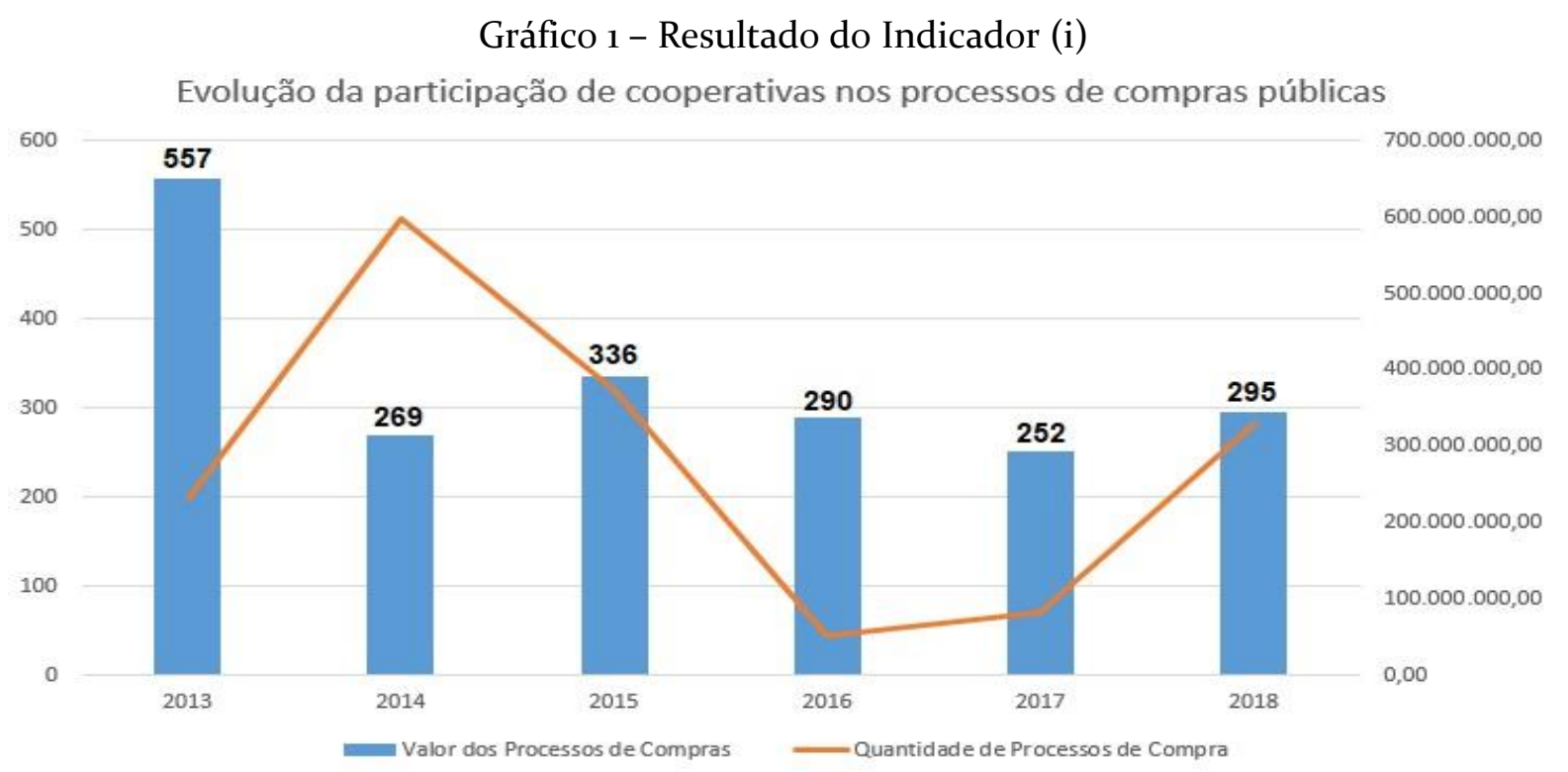

Fonte: Elaboração das autoras

No que concerne ao indicador (ii), utilizado para verificar a evolução temporal da participação da área de atividade das cooperativas vencedoras dos processos de compras públicas, ao comparar o primeiro e último ano aos quais se referem os dados, ou seja 2013 e 2018, foi possível 
identificar que houve crescimento de participação apenas na área transporte, que passou de 20 homologações em 2013 para 177 em 2018. Para as demais áreas houve diminuição na participação quantitativa, sendo que o setor de agropecuário caiu de 256 homologações em 2013 para 45 em 2018, o setor saúde diminuiu de 168 homologações em 2013 para 34 em 2018 e o setor produção de bens e serviços regrediu de 113 homologações em 2013 para 38 em 2018. Não é possível visualizar tendências homogêneas significativas para áreas de atuação nos anos intermediários, conforme se visualiza no gráfico 2.

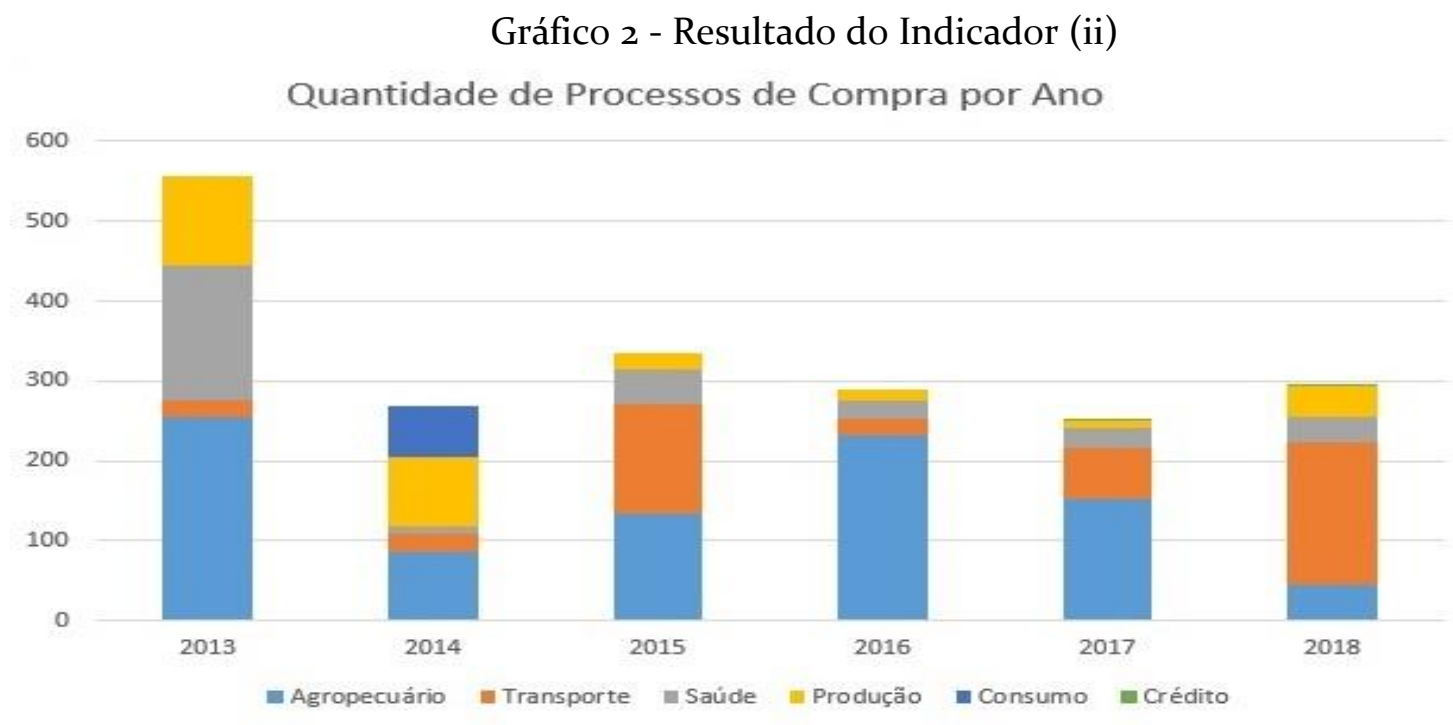

Fonte: Elaboração das autoras

Concernente ao indicador (iii), que pretendeu aferir a evolução temporal do valor financeiro das contratações relacionadas à área de atividade das cooperativas vencedoras, conforme se visualiza no gráfico 3, foi possível constatar que o setor agropecuário apresentou oscilações sucessivas dos valores homologados nos pregões no período em análise, sendo que os valores financeiros para os anos de 2013 a 2018, foram, respectivamente, do montante de $\mathrm{R} \$ 18$ milhões, $\mathrm{R} \$ 10$ milhões, $\mathrm{R} \$ 18$ milhões, R \$ 38 milhões, R 26 milhões e R \$ 4 milhões. A atividade relacionada ao transporte também apresentou oscilações no período analisado, com valores nas homologações de R\$ 5 milhões em 2013 e 2014, aumentando para R\$ 83 milhões em 2015, diminuindo para R\$ 3 milhões em 2016 e 2017 e passando a $\mathrm{R} \$ 18$ milhões em 2018. O setor de saúde obteve a maior participação financeira nos valores homologados às cooperativas no período analisado, com destaque para o resultado obtido nas homologações dos anos de 2013 a 2015, cujo valor obtido soma aproximadamente R\$ 1 bilhão. No ano de 2016, ocorreu acentuada queda nas homologações da área de saúde, com resultado obtido de R\$ 6 milhões. Nos anos de 2017 e 2018, as homologações para a área em comento voltaram a subir, atingindo o valor de R\$ 174 milhões no ano de 2018. Na análise dos montantes homologados para o setor de produção de bens e serviços, foi possível identificar elevado crescimento financeiro, de aproximadamente $700 \%$, ao comparar o primeiro e último ano aos quais se referem os dados, tendo em vista que o valor das contratações do ano de 2013 foi da ordem de R\$ 19 milhões e o valor das contratações para a área em 2018 foi de R 133 milhões. Por fim, a atividade de consumo apresentou um único resultado em homologações, ocorrido no ano de 2014, com valor de $\mathrm{R} \$ 71 \mathrm{mil}$. 


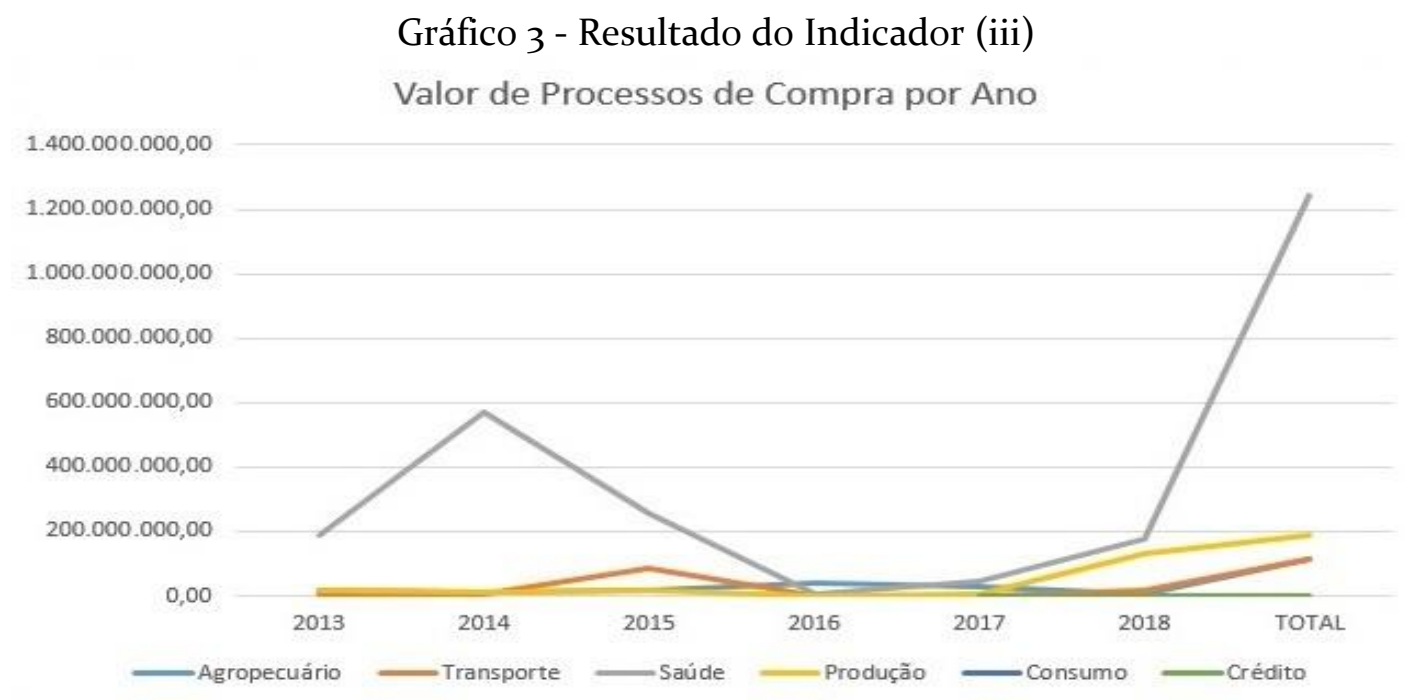

Fonte: Elaboração das autoras

No tocante ao indicador (iv), que teve por objetivo quantificar a participação da área de atividade nos processos de compras vencidos por sociedades cooperativas no período em análise, do resultado obtido, exposto no gráfico 4 , foi possível identificar que o setor agropecuário apresentou a maior participação quantitativa de adjudicações em pregões no período de 2013 a 2018, representando $45 \%$ das homologações. Na ordem decrescente de quantidade de homologações, seguem a área de transporte com $23 \%$, saúde com $15 \%$, produção de bens e serviços com $14 \%$ e consumo com $3 \%$. Cabe destacar que, a partir da análise deste indicador, foram excluídos 3 processos de compra, com valor aproximado de $\mathrm{R} \$ 22$ mil, relacionados a cooperativas de crédito. A exclusão se deu em decorrência do objeto da licitação se referir a cessão onerosa de uso para exploração de espaços físicos públicos, configurando contrato de despesa, que não coaduna com os objetivos de análise desta pesquisa.

Além da quantificação da participação das áreas de atividade econômica, na análise do indicador (iv) foi possível constatar que os 904 processos de compras do setor agropecuário foram adjudicados a 30 cooperativas, os 445 pregões do setor transporte abrangeram a contratação de 40 cooperativas, os 301 pregões da área de saúde tiveram 32 cooperativas vencedoras, os 281 processos de compra do setor de produção de bens e serviços tiveram 29 cooperativas vencedoras e os 65 pregões envolvendo a área de consumo tiveram uma única cooperativa como adjudicatária.

Gráfico 4 - Resultado do Indicador 4

Processos de Compras por Área de Atuação

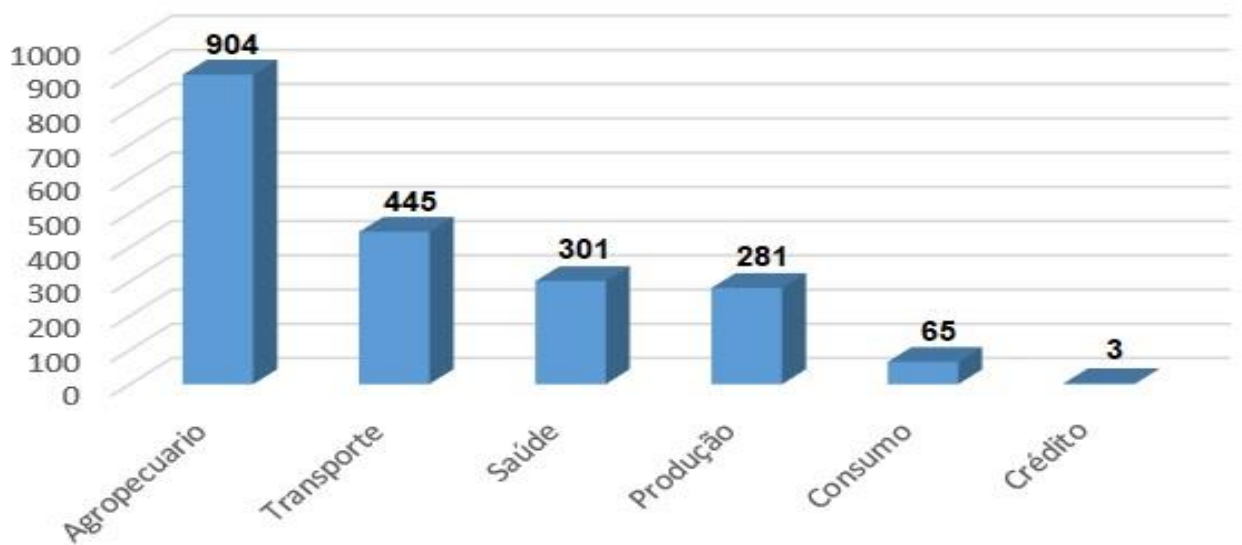

Fonte: Elaboração das autoras 
No tocante ao indicador (v), que teve por objetivo verificar participação da área de atividade no valor dos processos de compras vencidos por sociedades cooperativas, a área de saúde se sobressaiu no aspecto financeiro. Conforme exposto no gráfico 5 , o montante financeiro homologado às cooperativas desse setor foi da ordem de $R \$ 1.244 .996 .326,41$ (um bilhão, duzentos e quarenta e quatro milhões, novecentos e noventa e seis mil, trezentos e vinte e seis reais e quarenta e um centavos), representando $75 \%$ do valor dos pregões adjudicados no período analisado. $\mathrm{O}$ setor de produção de bens e serviços obteve participação financeira de R 187 milhões, representando $11 \%$ do montante homologado às cooperativas. No que concerne à área relacionada ao transporte, o valor homologado no período analisado foi da ordem de $\mathrm{R} \$ 116$ milhões, com representatividade de $7 \%$ do total de processos de compras. O setor agropecuário também obteve participação percentual de $7 \%$ do montante financeiro envolvido nas contratações em análise, em decorrência do seu resultado ser da ordem de R\$ 116 milhões. Em relação à área de consumo, foi possível observar a mais baixa participação financeira nos pregões homologados no período, o valor de $\mathrm{R} \$ 71$ mil envolvido nas contratações do representa $0,004 \%$ do montante adjudicado às cooperativas.

\section{Gráfico 5 - Resultado do Indicador 5 \\ Valor dos Processos de Compras por Área de Atuação}

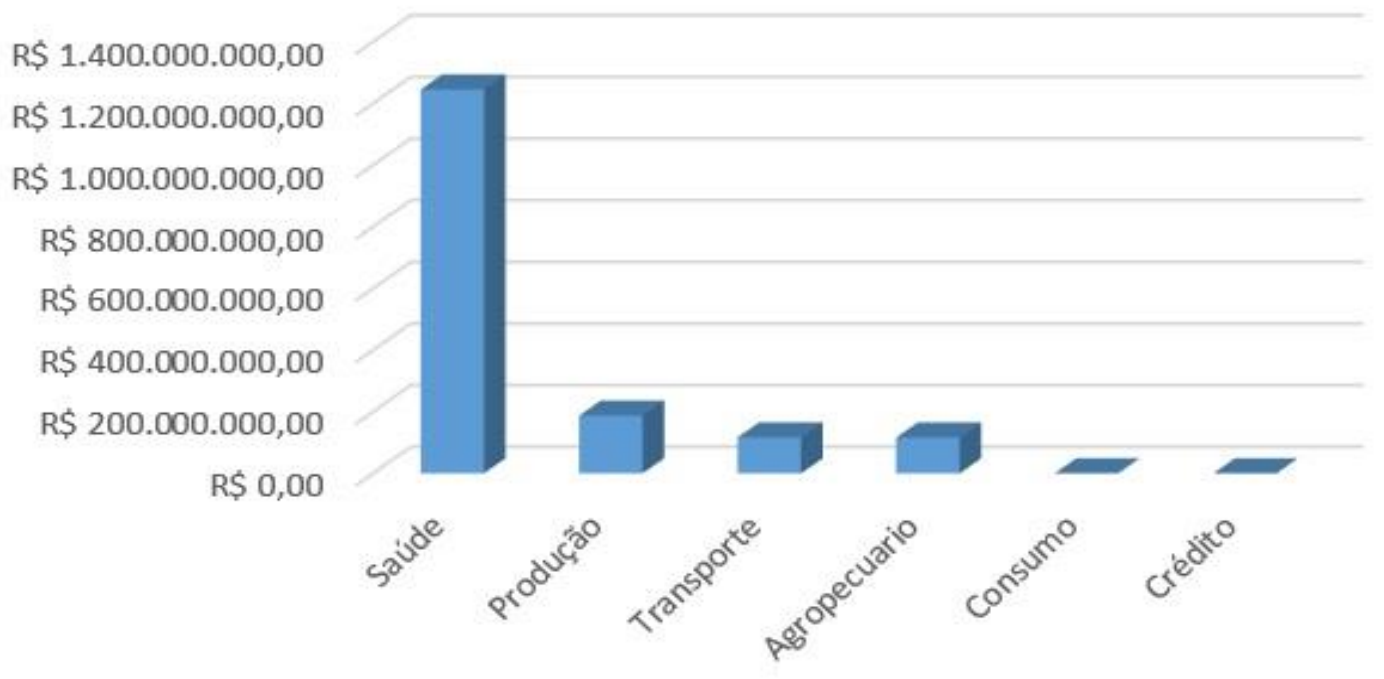

Fonte: Elaboração das autoras

O indicador (vi) teve a finalidade de verificar a relação existente entre a quantidade de processos de compras e o valor movimentado nas contratações, de acordo com as áreas de atuação às quais as cooperativas vencedoras estão vinculadas. Dessa forma, os resultados nos indicadores (iv) e (v) foram sobrepostos, conforme se verifica no gráfico 6 , possibilitando verificar inicialmente que o setor agropecuário possui a maior representatividade quantitativa, de $45 \%$ do total de processos de compras, porém, esse resultado não reflete no montante financeiro adjudicado às cooperativas dessa área de atuação, que responde por apenas $7 \%$ do valor total dos pregões vencidos por cooperativas, no período analisado. A área de saúde, de forma inversa, possui representatividade quantitativa de $15 \%$ do total de processos de compras, contudo, os montantes envolvidos nas contratações possibilitaram ao setor atingir $75 \%$ do valor total adjudicado às cooperativas. A área de transporte, por sua vez, possui representatividade quantitativa de $23 \%$ dos pregões vencidos, com resultado financeiro de $7 \%$ do montante envolvido nas contratações. No que concerne ao setor de produção de bens e serviços, constatou-se que a participação quantitativa corresponde a $14 \%$ dos processos de compras, que possibilitaram à área atingir $11 \%$ do montante financeiro total homologado nas licitações analisadas. A área consumo, com 3\% de representação quantitativa, possui o,004\% de participação financeira em relação ao valor total de processos de compras realizados entre 2013 e 2018 e adjudicado às sociedades cooperativas. 
Gráfico 6 - Resultado do Indicador 6

\section{Quantidade de processo de compras públicas e valor das contratações}

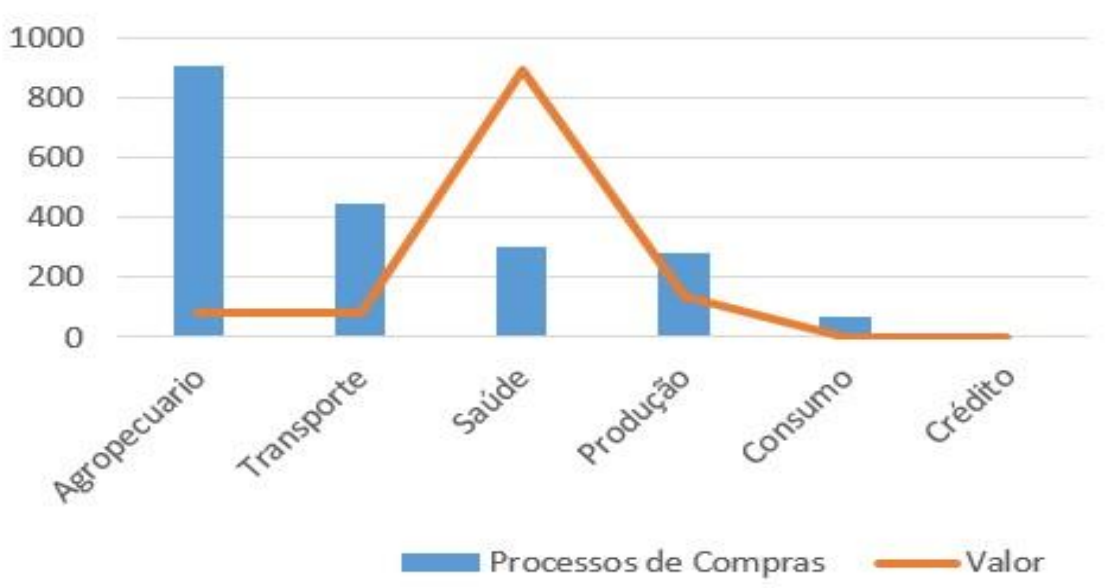

R\$ $1.400 .000 .000,00$

$\mathrm{R} \$ 1.200 .000 .000,00$ $\mathrm{R} \$ 1.000 .000 .000,00$ R\$ $800.000 .000,00$ R\$ $600.000 .000,00$ R\$ 400.000.000,00 R\$ 200.000.000,00 $\mathrm{R} \$ 0,00$

Fonte: elaboração das autoras

Esgotados os resultados a serem apresentados em resposta aos indicadores, restou caracterizada a participação das cooperativas em 1999 processos de compras ocorridos no período de 2013 a 2018 nos quais 134 sociedades foram vencedoras das licitações realizados na modalidade pregão. Destarte, cabe apresentar a análise comparativa dos resultados obtidos na participação das cooperativas em relação à totalidade de processos de compras realizados na modalidade pregão no mesmo período avaliado.

Dessa forma, por meio de consulta ao Painel de Compras do Governo Federal, foi possível verificar que no período em análise foram realizados o total de 111.042 processos de compras na modalidade pregão, nos quais o montante financeiro envolvido nas contratações foi da ordem de R\$ $\mathrm{R} \$ 122.105 \cdot 347.688,23$ (cento e vinte e dois bilhões, cento e cinco milhões, trezentos e quarenta e sete mil, seiscentos e oitenta e oito reais e vinte e três centavos). Os processos de compra envolveram a participação de 16.731 fornecedores, considerando todos os portes.

Isto posto, é possível inferir que as cooperativas tiveram participação de $1,80 \%$ na quantidade total de processos de compras realizados pela Administração Pública, de 1,36\% no valor total dos pregões homologados e de $0,80 \%$ do total de fornecedores contratados.

Ainda como resultado a ser apresentado neste estudo, foi considerado o comparativo dos percentuais das participações quantitativa e financeira obtidas pelas cooperativas e pelas ME/EPP, em função do previsto no art. 34, da Lei 11.488/2007, que as equipara, concedendo àquelas o tratamento diferenciado concedido a estas por força da Lei Complementar 123/2006.

Nesse sentido, foi possível verificar nos dados do Painel de Compras que as ME/EPP foram vencedoras de $89,32 \%$ dos processos de compras, enquanto as cooperativas venceram em 1,80\%. Quanto ao valor homologado no período, a participação das ME/EEP representou 47,80\% do valor total das contratações, enquanto as cooperativas participaram em 1,36\% do valor total.

\section{Considerações Finais}

A caracterização da participação das sociedades cooperativas como vencedoras de processos de compras realizados na modalidade pregão no período de 2013 a 2018 revelou a baixa representatividade dessas instituições em relação ao quantitativo de licitações realizados pela Administração Pública $(1,80 \%)$, em relação ao valor financeiro envolvido nas contratações públicas $(1,36 \%)$ e em relação à sua representatividade dentre os fornecedores contratados pela Administração Pública $(0,80 \%)$.

Com esteio nos resultados, é possível concluir que apenas 1,97\% das cooperativas brasileiras foram contratadas por meio de processos licitatórios promovidos pela Administração Pública. Como 
limitação desse resultado, destaca-se que foi considerada a quantidade de 134 cooperativas vencedoras nos processos de compras e a existência de 6,8 mil cooperativas no Brasil, conforme informação fornecida pela OCB e já referenciada neste estudo.

Em que pese os benefícios concedidos às cooperativas pela Lei 11.488/2007, que as equiparou às ME/EPP para fins de tratamento favorecido nas licitações, tal política de compra governamental não produziu equiparação nos resultados por elas obtidos. Enquanto as ME/EPP venceram 89,32\% dos pregões, as cooperativas venceram 1,80\% e à medida em que as ME/EPP participaram em 47,80\% do valor contratado nos pregões, as cooperativas participaram em apenas 1,36\% do valor contratado.

Os resultados apresentados neste estudo convergem para o entendimento de que os normativos editados em sede de política de compra governamental não alcançaram efetividade no dever de apoio e de estímulo ao cooperativismo, consagrado na Carta Magna. Ainda que haja necessidade de maior aprofundamento na análise, é possível inferir dos resultados que as medidas restritivas e de vedação à participação de cooperativas nas licitações foram efetivas na sua finalidade, e lograram êxito em afastar essas sociedades dos certames.

Porém, conforme se colige das possíveis mudanças do cenário jurídico apresentadas neste estudo, a possibilidade de transformação do arcabouço legal e jurisprudencial passa a ser uma oportunidade para as cooperativas ocuparem o vácuo de representatividade no mercado das compras governamentais. Aliada a essa possibilidade, situa-se a necessidade de se evidenciar o potencial das sociedades cooperativas, pelo alinhamento do movimento cooperativista aos ODS, atuarem como parceiras do Estado em prol do desenvolvimento nacional sustentável. Nesse escopo de abordagem, e pelas limitações desta pesquisa, se sugere o aprofundamento em estudos futuros.

\section{Referências}

ACOCELLA, Jéssica; RANGEL, Juliana Cabral Coelho. O papel regulatório e de fomento das licitações públicas. Revista do BNDES, Rio de Janeiro, n. 40, p. 269-312, dez. 2013

BARARDEL, Evandro Meira. Licitação como instrumento de política pública de desenvolvimento regional / Evandro Meira Baradel. - 2011.91 f., disponível em bibliotecadigital.fgv.br/dspace/handle/10438/9241. Acesso em 30 Mar. 2019.

BRASIL. Constituição da República Federativa do Brasil de 1988. Brasília, 5 de outubro de 1988.

BRASIL. Lei no. 5.764, de 16 de dezembro de 1971, Define a Política Nacional de Cooperativismo, institui o regime jurídico das sociedades cooperativas, e dá outras providências.

BRASIL. Lei no 8.666, de 21 de junho de 1993. Institui as normas para licitações e contratos da Administração Pública.

BRASIL. Lei n.12.527, de 18 de novembro de 2011. Regula o acesso a informações previsto no inciso XXXIII do art. 50, no inciso II do § 30 do art. 37 e no § 20 do art. 216 da Constituição Federal; e dá outras providências.

BRASIL. Lei no 12.69o, de 19 DE julho de 2012, Dispõe sobre a organização e o funcionamento das Cooperativas de Trabalho; institui o Programa Nacional de Fomento às Cooperativas de Trabalho PRONACOOP; e revoga o parágrafo único do art. 442 da Consolidação das Leis do Trabalho - CLT, aprovada pelo Decreto-Lei no 5.452, de 1을 de maio de 1943.

BRASIL. Lei Complementar 123, de 14 de dezembro de 2006. Institui o Estatuto Nacional da Microempresa e da Empresa de Pequeno Porte; altera dispositivos das Leis no8.212 e 8.213, ambas de 24 de julho de 1991, da Consolidação das Leis do Trabalho - CLT, aprovada pelo Decreto-Lei no 5.452, de 10 de maio de 1943, da Lei no 10.189, de 14 de fevereiro de 2001, da Lei Complementar no 63, de 11 
de janeiro de 1990; e revoga as Leis no 9.317, de 5 de dezembro de 1996, e 9.841, de 5 de outubro de 1999 .

BRASIL. Decreto-Lei n.ํㅜ 5.452, de 1º de maio de 1943, Aprova a Consolidação das Leis do Trabalho.

BRASIL. Lei 11.488, de 15 de junho de 2007, Cria o Regime Especial de Incentivos para o Desenvolvimento da Infra-Estrutura - REIDI; e dá outras providências.

FENILI, Renato. Governança em aquisições públicas: teoria e prática à luz da realidade. Niterói, RJ: Impetus, 2018, $380 \mathrm{p}$.

FRANKE, Walmor. Direito das sociedades cooperativas. São Paulo: Saraiva, 1973.

GAUDIO, Ronaldo Chaves. Marco Legal brasileiro das cooperativas de trabalho: busca pelo direito adequado em meio ao discurso jurídico reacionário. in. Cooperativa de las Américas, Región de la Alianza Cooperativa Internacional. Congreso Continental de Derecho Cooperativo coordinado por Dante Cracogna. $1^{\underline{a}}$ Ed. - Ciudad Autónoma de Buenos Aires: intercoop, Cooperativa de las Américas, 2014 .

GUEDES, Aloysio Neves. O procedimento licitatório como microssistema jurídico: apontamentos e reflexões. Rio de Janeiro (Estado). Tribunal de Contas. Revista do Tribunal de Contas do Estado do Rio de Janeiro - v. 2, n. 5 (jan./jun. 2013) Rio de Janeiro: O Tribunal.

INÁCIO, Edmundo Jr.; RIBEIRO, Cássio Garcia. O mercado de compras governamentais brasileiro: aspectos metodológicos e de mensuração. Cadernos de Finanças Públicas , v. 14, p. 265-287, 2014.

JUSTEN FILHO, Marçal. Curso de Direito Administrativo brasileiro. 16. ed. ver. e atual. São Paulo: Saraiva. 2009, p. 374.

LAKATOS, E. M.; MARCONI, M. A. Fundamentos de metodologia científica. -6. ed. - São Paulo: Atlas, 2008.

MACHADO, Tiago. A suposta subordinação de atividades como causa impeditiva para atuação das cooperativas de trabalho./ Tiago Machado - Porto Alegre: Sescoop/RS, 2017.

MINAYO, Maria Cecília de Souza (org.). Pesquisa Social. Teoria, método e criatividade. 18 ed. Petrópolis: Vozes, 2001.

NASCIMENTO, André Jansen. O microssistema de contratação de defesa: a licitação como instrumento de política pública de defesa no Brasil. Brasília, 2014. 264 p. Dissertação de Mestrado Centro Universitário de Brasília

OLIVEIRA, Thiago Bueno. O caráter regulatório das licitações públicas. Brasília: Abecer, 2012. 220 p.

REISDORFER, Vitor Kochhann. Introdução ao cooperativismo. Colégio Politécnico (UFSM). Santa Maria-RS. 2014.

SÚMULA TCU 281, disponível em https://pesquisa.apps.tcu.gov.br/\#/documento/ sumula/\%252a/NUMERO\%253A281/DTRELEVANCIA\%252odesc/o/sinonimos\%3Dfalse, acesso em 14 mai. 2018. 
OCB - ORGANIZAÇÃO E SINDICATO DAS COOPERATIVAS BRASILEIRAS. Áreas de atuação prioritárias. Disponível em: http://www.ocb.org.br/site/sescoop/ atuação.asp. Acesso em: 24 jan. 2014.

${ }^{\mathrm{i}}$ Disponível em https://www.ica.coop/en/cooperatives/what-is-a-cooperative, acesso em 21 mai. 2019.

${ }^{i i}$ Disponível em https://somoscooperativismo.coop.br/o-que-e-cooperativismo, acesso em 27abr. 2019.

iii Disponível em: https://www.agendainstitucional.coop.br/agenda2019_web.pdf, acesso em 20 mai. 2019.

iv Disponível em https://somoscooperativismo.coop.br/publicacao/57/ramos-do-cooperativismo, acesso em 26 abr. 2020.

Disponível em https://legis.senado.leg.br/sdleg-getter/documento?dm=4424626\&ts=155320 5284537\& disposition=inline, acesso em 3 mai.2019.

${ }^{v i}$ Disponível em https://nacoesunidas.org/pos2015/agenda2030/2/. Acesso em 18 mai. 2019.

vii Disponível em https://www.somoscooperativismo.coop.br/noticia/21138/ cooperativismo-e-onu-oficializamparceria. Acesso em 18 mai. 2019.

viii Disponível em https://www2.camara.leg.br/atividade-legislativa/comissoes/comissoes-temporarias/especiais/55alegislatura/pl-6814-17-licitacoes/documentos/outros-documentos/quadro-comparativo-pl-6814-17-e-substitutivo-doparecer-versao-03-12.2018, acesso em 20 mai. 2019.

ix Disponível em https://pesquisa.apps.tcu.gov.br/\#/documento/jurisprudencia-selecionada/*/ KEY:JURISPRUDENCIA-SELECIONADA-70767/score\%20desc,\%20COLEGIADO , acesso em 15 mai. 2019.

${ }^{\mathrm{x}}$ Disponível em https://www.comprasgovernamentais.gov.br/index.php/painel-de-compras-de-governo, acesso em 03 mar. 2019. 